\title{
Radio-Telemetry in Biomedical Research - Radio-Telemetry Blood Pressure Measurements in Animal Models of Hypertension, How It Revolutionized Hypertension Research
}

\author{
Pierre Dumas, Dan Chiche, Johanne Tremblay, \\ Ondřej Šeda, Junzheng Peng and Pavel Hamet \\ Centre for Ecogenomic Models of Human Diseases/CRCHUM, Technopôle Angus \\ Canada
}

\section{Introduction}

Radiotelemetry is employed in several fields to circumvent several issues: areas difficult or dangerous to access, monitoring of dangerous processes, need for secret monitoring. In biological sciences, telemetry is mainly useful because it decreases the observer bias and interference. In the field of medicine, the current research is mostly aimed at findings the cause and appropriate cures to common diseases. Common diseases are widely prevalent diseases for which we know only partially the causes and for which, as a consequence, we only propose treatments to alleviate the symptoms or their impacts on target organs. The common examples of such diseases to name a few are: diabetes, cancer(s), obesity, multiple sclerosis and hypertension, not to mention most of the psychiatric illnesses. They are characterized by a strong genetic component and a strong environmental influence since their prevalence is markedly influenced by age, diet, exercise or other environmental stressors. This important environmental modulation makes them more difficult to study. Therefore, our goal here will be to illustrate the challenge of studying environmentmodulated traits. With hypertension as an example, we will describe the use and benefits of employing radiotelemetry in hypertension research in order to be able to subtract the role of the environment or, conversely to quantify its impact on blood pressure. In the current postgenome era, with enough financial support and colleagues from around the world, it has never been easier to design and perform huge genome-wide association studies to try to unveil the genetic determinants of common diseases. Each month, hundreds of loci are reported that are associated with a higher prevalence of diseases and single nucleotide polymorphisms covering the entire genome are proposed to be in linkage with disease genes. We also know that very few of these proposed loci end up being truly associated with diseases in replication studies and we will present the current arguments pro and against this approach in the field of hypertension. This, we hope, will illustrate the point that we want to make in this chapter: in order to perform valid genome-wide association studies in human or genetic studies in animal models to uncover the genetic determinants of common diseases, it is essential to clearly define the studied phenotype(s) and to ensure that their measurements are performed accurately with the least amount of confounders or artefacts. 
Our contribution to this book entitled "Telemetry" will not be of a technical nature nor will it systematically review in all details the merit of telemetry in our field of research because it would go beyond the scope of this book and would not be suited for a broad audience. We direct the interested readers to the review of Kurtz and colleagues (2005) for that purpose. We are presenting here an aspect of what we think is the most important contribution of telemetry in our field, its use to monitor blood pressure free of stress artefacts or on the contrary, its use to evaluate the contribution of this environmental "stress".

\section{Blood pressure and hypertension}

High blood pressure is a major risk factor for cardiovascular diseases. Because of its impact on cardiovascular diseases, their complications and the cost associated, it is important to evaluate its prevalence accurately. This essential data can then help design public health policies aimed at controlling high blood pressure in the population. With the example of recent Canadian epidemiological studies, we will try to demonstrate how the methods used to record blood pressure can affect the relative prevalence in the study population with direct consequences on public health policies. Our aim is to illustrate the importance of good phenotyping, a major challenge in hypertension research.

\subsection{Definition and prevalence of hypertension}

Blood pressure is a continuous quantitative trait genetically determined but under the strong influence of the environment. It is a consistent and independent risk factor for cardiovascular and renal diseases. At least one third of adult United States population have hypertension defined as systolic blood pressure $\geq 140 \mathrm{~mm} \mathrm{Hg}$, diastolic blood pressure $\geq 90$ $\mathrm{mm} \mathrm{Hg}$ and/or current use of antihypertensive medication (Brown et al., 2001). It is a major risk factor for premature cardiovascular morbidity and mortality (Lawes et al., 2008). Epidemiologic studies have indicated that, for people 40-69 years of age, each increase of 20 $\mathrm{mm} \mathrm{Hg}$ in usual systolic blood pressure is associated with a doubling of mortality rates for stroke and ischemic heart disease (Lewington et al., 2002). Hypertension is considered by the World Health Organization to be the number one risk factor for death in the world in both developed and developing countries, responsible for an estimated 7.5 million deaths per year $(12.8 \%$ of all deaths).

\subsection{Situation in Canada}

The prevalence of hypertension in Canada was recently assessed in four population-based studies between 1986 and 2009 (Table 1). Blood pressure measurement was performed in all but one study (Canadian Community Health Survey). An automated device, BpTRU was used for the two most recent studies (Leenen et al., 2008; Wilkins et al., 2010), whereas blood pressure was measured by a trained nurse in the other one (Joffres et al., 2001). The Canada Heart Health Study (Joffres et al., 2001) has been conducted from 1986 to 1992 as a population-based cross-sectional study to estimate the prevalence and distribution of elevated blood pressure among Canadian adults. A probability sample of 23,111 men and women aged 18 to 74 years were selected from the health insurance registers in each province. Mean of all available blood pressure measurements from four measurements was used. The rate of subjects with hypertension, defined by systolic BP at or above $140 \mathrm{mmHg}$ or diastolic BP at or above $90 \mathrm{mmHg}$ or treatment for hypertension was $21.1 \%$. The proportion of hypertensive subjects unaware of their hypertension was $43 \%$. The level of 
hypertensive subjects aware but not treated and not controlled was $22 \%$ while $21 \%$ percent were treated and not controlled, and only $13 \%$ were treated and controlled. At that time, although the prevalence of hypertension was similar in Canada and the United States, levels of awareness, treatment and control were higher in the United States. Leenen et al. (2008) have conducted a survey to evaluate the current prevalence and management of hypertension among adults in the province of Ontario. Blood pressures, measured with an automated device, were obtained for 2,551 of the respondents (age 20-79 years). Hypertension, defined as systolic blood pressure of $140 \mathrm{~mm} \mathrm{Hg}$ or more, diastolic blood pressure of $90 \mathrm{~mm} \mathrm{Hg}$ or more, or treatment with an antihypertensive medication, was identified in $21.3 \%$ of the population overall (23.8\% of men and $19.0 \%$ of women). Prevalence increased with age, from 3.4\% among participants $20-39$ years of age to $51.6 \%$ among those 60-79 years of age. Hypertension was more prevalent in black people and people originating from South Asia than among white people; hypertension was also associated with higher body mass index. Among hypertensive participants, $65.7 \%$ were undergoing treatment with control of hypertension, $14.7 \%$ were undergoing treatment but the hypertension was not controlled, and 19.5\% were not receiving any treatment (including $13.7 \%$ who were unaware of their hypertension).

The latest Canadian report was published in 2010 by Wilkins et al (2010) with cycle 1 of the Canadian Health Measures Survey, conducted from March 2007 through February 2009 in 15 sites across Canada. This survey comprised a population-based sample and included direct BP measures using an automated device. During an interview, 3,514 subjects were asked two questions about BP: whether they had high BP diagnosed by a health professional and whether they had taken "medicine for high blood pressure" in the past month. BP measures were obtained at a mobile examination centre a few days after the initial interview. BP values were calculated by taking the average of the last five of six measures (taken one minute apart) of valid BP measurements. Results among adults aged 20 to 79 years showed that hypertension (systolic BP higher than or equal to 140 or diastolic BP higher than or equal to 90 $\mathrm{mmHg}$, or self-reported recent medication use for high BP) was present in 19\%. Of those with hypertension, $83 \%$ were aware, $80 \%$ were taking antihypertensive drugs, and $66 \%$ were controlled. With regards to the significant progress observed compared to Joffres et al report (1992), the authors conclude that their results are consistent with the large improvements in diagnosis, treatment and drug prescriptions for hypertension that have recently occurred in Canada (Campbell et al., 2009; Hemmelgarn et al., 2008). In the late 1990s, extensive efforts have been underway in Canada to improve physician and public awareness of the importance of diagnosis, treatment and control of hypertension, including the Canadian Hypertension Education Program (http://www.hypertension.ca/chep), yet the author cautioned against a potential overestimation of this change, particularity as it makes Canada being out of the range of other countries.

Table 1 reports the main results from these 4 studies. When measured, the prevalence of hypertension is quite stable between 19 and $21.3 \%$. The rate of hypertensive patients unaware of their condition has dramatically decreased from $43 \%$ to $16.6 \%$. In addition, the rate of treated and controlled hypertensive patients among hypertensive population seems to have dramatically increased as well from $13 \%$ to $65.9 \%$. This trend was still observed in treated hypertensive population taking into consideration the differences in the number of hypertensive patients aware of their condition and treated. Nevertheless, this comparison must be interpreted with caution since there are many differences in methodological approaches, mainly the use of an automated device known to report lower BP values. 


\begin{tabular}{|c|c|c|c|c|c|c|c|c|}
\hline Name, author & 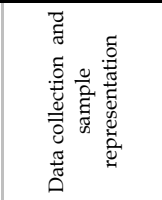 & Blood pressure measurement & $\begin{array}{l}\text { Definition of } \\
\text { hypertension }\end{array}$ & $\begin{array}{l}\text { Study } \\
\text { Period }\end{array}$ & $\begin{array}{c}\text { Preva- } \\
\text { lence }\end{array}$ & 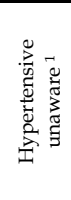 & 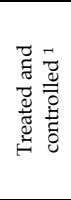 & 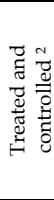 \\
\hline $\begin{array}{c}\text { Canadian Heart } \\
\text { Health Surveys, } \\
\text { Joffres et al., } \\
1992\end{array}$ & $\begin{array}{c}\text { Population } \\
\text { based, 18-74 } \\
\text { year, Interview } \\
\text { and clinic visit }\end{array}$ & $\begin{array}{l}\text { Two BP measurements: one } \\
\text { at the beginning of the } \\
\text { interview and one at the end, } \\
\text { twice, } 2 \text { weeks apart. The BP } \\
\text { was measured by a trained } \\
\text { nurse. Standardization for } \\
\text { identification of the } \\
\text { Korotkoff sounds. Correctly } \\
\text { sized cuffs were used. Quiet } \\
\text { for } 5 \text { min, sitting position, } \\
\text { Right arm (if possible) The } \\
\text { mean BP (four } \\
\text { measurements for most } \\
\text { participants) was used. }\end{array}$ & $\begin{array}{l}\text { Mean SBP/DBP } \\
\text { of } 140 / 90 \mathrm{~mm} \\
\text { Hg or medication }\end{array}$ & 1986-1992 & $21.1 \%$ & $43 \%$ & $13 \%$ & $38 \%$ \\
\hline $\begin{array}{c}\text { Canadian } \\
\text { Community } \\
\text { Health Survey } \\
\text { Campbell et al., } \\
2008\end{array}$ & $\begin{array}{c}\text { Canadians aged } \\
12 \text { and over. } \\
65,000 \\
\text { representative } \\
\text { of } 121 \text { Health } \\
\text { Regions } \\
\text { Computer- } \\
\text { Assisted } \\
\text { Personal } \\
\text { Interview or } \\
\text { Telephone } \\
\text { Interview }\end{array}$ & None & $\begin{array}{l}\text { Population aged } \\
12 \text { and over who } \\
\text { report that they } \\
\text { have been } \\
\text { diagnosed by a } \\
\text { health } \\
\text { professional }\end{array}$ & $\begin{array}{c}2001,2003, \\
2005,2007, \\
\text { (yearly) }\end{array}$ & $\begin{array}{l}16.4 \% \\
(2008)\end{array}$ & NA & NA & NA \\
\hline $\begin{array}{c}\text { Ontario Survey } \\
\text { on the } \\
\text { Prevention and } \\
\text { Control of } \\
\text { Hypertension } \\
2006, \\
\text { Leenen et al., } \\
2008\end{array}$ & $\begin{array}{c}\text { Random } \\
\text { dwellings, } 2551 \\
\text { participants, 20- } \\
79 \text { years, } \\
\text { Ontario }\end{array}$ & $\begin{array}{c}\text { Arm circumference } \\
\text { measured for selection of } \\
\text { cuff. Cuff placed on left arm. } \\
\text { Seated and quiet for } 5 \\
\text { minutes. } 6 \text { measures and } 5 \\
\text { records using BpTRU }\end{array}$ & $\begin{array}{l}\text { Mean SBP/DBP } \\
\text { of } 140 / 90 \mathrm{~mm} \\
\text { Hg or treatment } \\
\text { with } \\
\text { antihyperten sive } \\
\text { drugs }\end{array}$ & $\begin{array}{l}\text { Published } \\
\text { in } 2008\end{array}$ & $21.3 \%$ & $13.7 \%$ & $65.7 \%$ & $77 \%$ \\
\hline $\begin{array}{c}\text { Canadian } \\
\text { Health Measures } \\
\text { Survey, } \\
\text { Wilkins et al., } \\
2010\end{array}$ & $\begin{array}{l}\text { Population } \\
\text { based, } \\
\text { Interview, } \\
\text { home and } \\
\text { mobile center } \\
\text { visits, 20-79 } \\
\text { years }\end{array}$ & $\begin{array}{l}\text { BpTRU - Average of the last } \\
\text { five measures of a set of six } \\
\text { taken one minute apart. }\end{array}$ & $\begin{array}{l}\text { Mean SBP/DBP } \\
\text { of } 140 / 90 \mathrm{~mm} \\
\mathrm{Hg} \text { or self- } \\
\text { reported recent } \\
\text { medication use } \\
\text { for high BP. }\end{array}$ & 2007-2009 & $19 \%$ & $16.6 \%$ & $65.9 \%$ & $82 \%$ \\
\hline
\end{tabular}

${ }^{1}$ Among hypertensive population; ${ }^{2}$ Among treated for hypertension population.

Table 1. Recent Canadian population-based studies estimating the prevalence of hypertension.

\subsection{Measurement bias}

It is well recognized that the method used for BP measurement has a very significant impact on the results. As an example, we compared Joffre et al. (2001) results to that of Wilkins et al. (2010) in the younger group age (respectively 18 to 34, and 20 to 39) where the prevalence of hypertension is very rare (below $5 \%$ ) with limited impact on mean systolic and diastolic BP. Mean SBP are significantly higher in male and female in Joffres et al. publication when compared to Wilkins et al.: in the range of 120/110 (male/female) as compared to 110/101, respectively. Similarly, DBP are 75/70 versus 72/67, respectively. Therefore, the remarkable improvement in the proportion of hypertensive subjects that are treated and controlled 
should be considered with caution, given the facts that the BP measurement protocols were different, with the most recent publications reporting lower BP values. An important advantage of an automated device is that it enables BP to be measured in the absence of another person. Its use, therefore, eliminates observer errors such as digit bias, zero preference and incorrect deflation rates, and also reduces "white coat hypertension". However, this specific device discard the first two readings, leading to elimination of highest pressures and these numbers were never validated for outcomes. According to the 2010 CHEP Recommendations for the Management of Hypertension (Hackam et al., 2010), home SBP values $>135 \mathrm{mmHg}$ or DBP values $>85 \mathrm{mmHg}$ using an automated device should be considered elevated and associated with an increased overall mortality risk analogous to office SBP readings of $>140 \mathrm{mmHg}$ or DBP $>90 \mathrm{mmHg}$. Hence, maybe less emphasis should be put on the $140 / 90 \mathrm{~mm} \mathrm{Hg}$ threshold with the more and more systematic use of automated devices for BP measurements in a controlled environment.

Thus, one should asks if these measurements are really reflecting the 'usual' blood pressure of an individual, knowing that the protocol demands that the first two values (always higher) be discarded and that the measurement be performed in a silent closed room without an observer. Does it really reflect the 'true' blood pressure and its minute-to-minute variability? Therefore, there is clearly a need to assess precisely blood pressure in humans since its 'usual value' as so much to do with the risk of cardiovascular events. Telemetric determination of blood pressure in human to assess its 'true values', its variations over time and the effect of antihypertensive medications would indeed be welcomed.

\subsection{Portapres, the only system that comes close to telemetry for blood pressure determination in humans}

Protocols and recommendations for blood pressure measurement in humans are available and they provide information for procedures in the clinical settings or at home and insist on the training of the observer (Pickering et al., 2005). Among the methods described, they cite the 100-year old auscultatory method employed with a stethoscope and a sphygmomanometer. It is based on the Korotkoff technique and uses a cuff placed around the upper arm and inflated above systolic pressure to occlude the brachial artery. The stethoscope is used to listen to the sounds of the pulsatile blood flow while the cuff is slowly deflated. Despite its accuracy, the classic mercury sphygmomanometer tends to disappear because of the hazard from mercury and is replaced by aneroid or hybrid sphygmomanometer. Other technologies and automated devices are also available, and the interested reader is directed to the review by Pickering et al. (2005) for details. Of note, the Korotkoff technique tends to underestimate the systolic blood pressure and overestimate the diastolic blood pressure when compared to intra-arterial pressure (Holland \& Humerfelt, 1964). With technology advances, battery-powered automated devices are now available to measure and record ambulatory blood pressure. They employ the same upper arm cuff and, because of the time required for one measurement they cannot record rapid changes in blood pressure. Furthermore, a maximum of four measurements per hour for 24 hours are usually obtained because of the annoyance of having the device squeeze the arm at regular interval. Nevertheless, ambulatory blood pressure monitoring can be very useful for diagnostic to ascertain blood pressure level outside the clinic. It also provides good information about blood pressure pattern during sleep.

There is, however, a method for blood pressure determination in humans that comes close to a telemetric method: the finger cuff method of Peñaz (1973). It is available commercially 
under the name Finapres or Portapres (Wesseling et al., 1995; Finapres Medical Systems BV, Amsterdam, The Netherlands). Despite being cumbersome, the Portapres enables reading to be recorded over 24 hours while the subject is ambulatory (Omboni et al., 1995; Parati et al., 1996). A photoplethysmograph under a finger cuff detects the pulsation of the blood flow. The inflation is continuously adjusted by a servo-loop according to the output of the plethysmograh to keep the output constant. As a result, the artery is kept in a partially open state. The pressure oscillations of the cuff were found to resemble to the intra-arterial pressure curve. Hence, this method gives an accurate estimate of the rapid changes in blood pressure although it usually underestimates 'true' systolic and diastolic pressures. Monitoring of blood pressure variations may prove to be of high clinical significance as several reports indicate a striking relationship between blood pressure variability and stroke (Rothwell, 2010; Rothwell et al., 2010).

In conclusion, the techniques for blood pressure determination in humans provide relatively accurate values of systolic and diastolic blood pressure. But, for most of them, quality measurements and reproducibility are greatly dependent on good calibration of the equipment, the environment where the measurements are taking place and training of the personnel performing them. Finally, only the finger-cuff method provides high accuracy of blood pressure changes with a high, beat-to-beat, measurement frequency. Since it is not invasive and enables recording in ambulatory subjects in their real life activities, this is the closest to a telemetric method when it comes to blood pressure determination in humans. In addition we should not hide that its cost and the technical expertise it requires are also something it shares with telemetry...

\subsection{Methods to unveil the genetic basis of hypertension - Need to define high blood pressure}

With what we have presented in mind, we will now conclude this section by presenting the challenges that our field of research is facing. Hypertension stems from a combination of genetic and environmental factors. The blood pressure variance commonly attributed to the genetic component is estimated between $30 \%$ and $50 \%$ (Havlik et al., 1979). Moreover, from twin or family aggregation studies, the sibling recurrence risk of hypertension is estimated at 2,5 to 3,5 (relative risk of developing hypertension if a sibling is affected) (Tobin et al., 2007). This clearly demonstrates the important genetic basis of the disease. With the sequencing of the human genome in 2000 and the progress of the HapMap project, we entered the "genomic era». Nowadays, there are about one million single nucleotide polymorphisms available without counting other genetic polymorphisms like copy number variants. These can be used for genome-wide association studies (GWAS) to characterize thousands of individuals from cases and control population in order to localize the genetic differences associated with the disease or related quantitative traits. In the field of hypertension, several large GWAS and many meta-analyses of GWAS were performed. Many loci on several chromosomes associated with hypertension were unveiled (for review, see Dominiczak \& Munroe, 2010). Despite these successes, critics from the community state that only a very small amount of the blood pressure variance is explained by each of these variants (about $1 \mathrm{~mm} \mathrm{Hg}$ of systolic and $0,5 \mathrm{~mm} \mathrm{Hg}$ of diastolic pressure). They rightfully ask: can such small-effect alleles have such an important population-wide role to play in the aetiology of the disease? And, with regard to the very high cost of these GWAS, is it worth continuing in the same direction with bigger and bigger study populations (Kurtz, 2010)? The proponents of the GWAS insist that the progress made in understanding the 
pathophysiology of the disease are important whereas the opponents argue that none of the current high-blood pressure drug-target were unveiled with GWAS and that finding thousands of common genetic variants with minute effects on blood pressure is of no use for the development of new drugs or the understanding of the disease.

While recognizing the power of GWAS and the fine-mapping capabilities of the current genomic technologies, we think that the accumulation of data from large studies is of no use if this data is not accurate and reliable. Currently, significant efforts are spent to standardize large population studies (Knoppers et al., 2008). On the long term, this would permit the merging of several studies with similar design in order to pool the data and increase the statistical power. In addition to standardization, we think also that the definition of the traits to be phenotyped is cardinal to any study. Only when that is done precisely and agreed on can the methods for measuring them be standardized. As we have seen from the Canadian experience, in an effort to standardize blood pressure measurements in the clinic as well as for the multicentre GWAS, more and more automated devices were employed in rigorous conditions with rejections of the first, higher, blood pressure values. As a result, the prevalence of hypertension has dramatically decreased in the last ten years. On the optimistic side, it may indicate an impact of the public health campaign and compliance to drug regimen by the patients. On the other hand, it may just reflect 'wrong' phenotyping. As we will demonstrate in the remaining of this chapter, because up to $70 \%$ of the blood pressure variance can be of environmental origin, it is essential to take the impact of the environment into account. If it is somewhat subtracted by 'overstandardization', blood pressure values may underestimate the 'true' blood pressure, and we may end up never finding high blood pressure genes because very few people will ever display high blood pressure in those settings. We should also mention the fact that studies rarely try to discriminate between supine, standing or seated blood pressure and that the blood pressure medication is usually not withdrawn prior to measurements because of the risks (ethical concerns) or the cost of monitoring the patients during that time. For instance, we have shown that the impact of the fto gene on blood pressure is dependent on the body position (sympathetic modulation) and responsive to stress (Pausova et al., 2009). As we will try to demonstrate in animal models of hypertension, we think that it is important to understand what we are measuring. We will now present a section explaining how to study genes that are sensitive to the environment and how to measure the traits that are modulated by the environment. We will then show how telemetry is suitable to achieve this very specific endeavour in research with animal models with some examples from our group.

\section{Genes $\mathrm{X}$ environment interactions, impact on blood pressure and development of hypertension}

Up to $70 \%$ of blood pressure variance is attributed to the environment. The impact of the environment can be seen as additive or in interaction with genes. Figure 1 summarizes the possible contributions of genes and environment to hypertension.

In the first case (a), the genes and the environment exert their influence on blood pressure independently. Thus, a disease gene (Gd) and a deleterious environment (Ed) would act separately to cause hypertension in an additive manner. In the second case (b), the environment is not "deleterious" per se. Its influence will depend on environment-sensitive genes (Gs). These are called susceptibility genes. They are not disease genes by themselves, they only permit the environment to reveal or amplify its impact. This is the $\mathrm{G} \times \mathrm{E}$ 
interaction. The best example in the field of hypertension is salt-sensitivity where only saltsensitive individuals are displaying hypertension consecutive to a higher intake of salt in the diet (Weinberger, 1990).

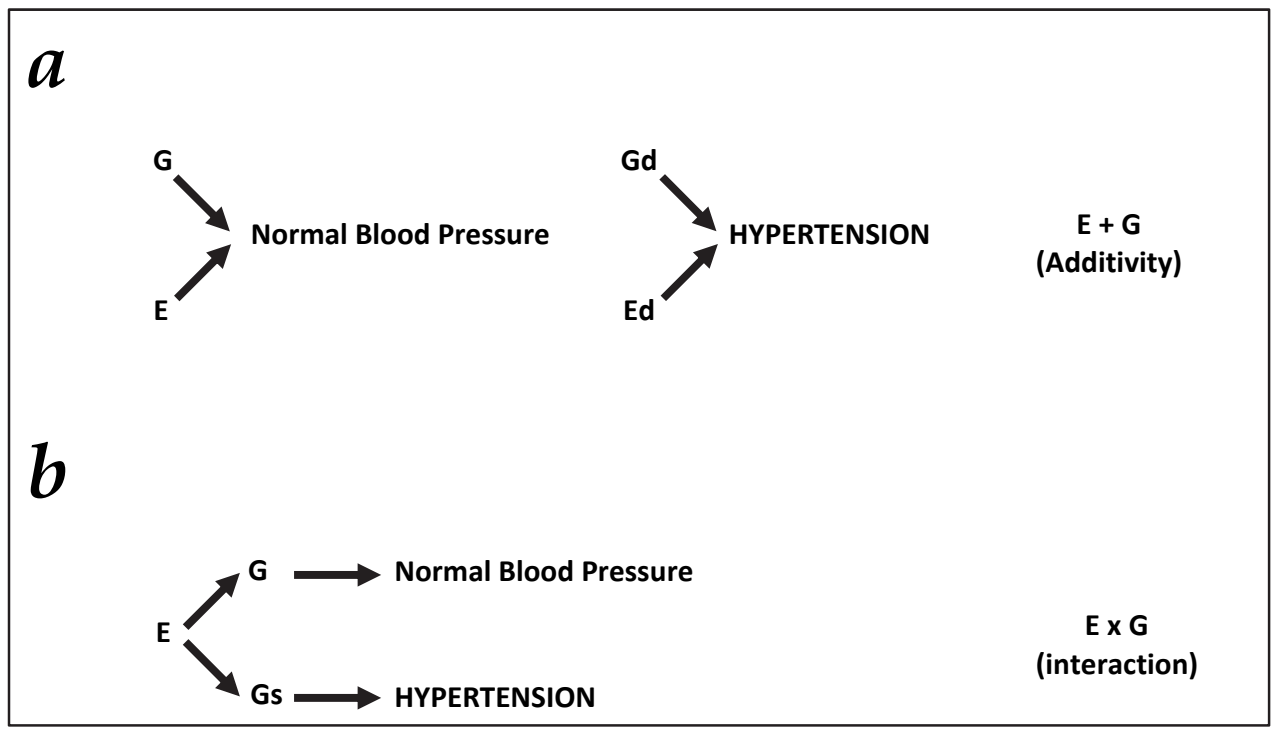

Fig. 1. Gene and environment in hypertension.

\subsection{How to approach the genes $X$ environment interactions - Concept of genetic susceptibility to the environment}

Thus, while a genetic polymorphism could be associated with an increased risk of developing a disease, a differential response to the environment could define a susceptibility to this environment. This environmental susceptibility being modulated by environmentsensitive genes, we proposed the concept of genetic susceptibility to the environment (Hamet, 1996; Hamet et al., 1998; Pausova et al., 1999). The hallmark of a susceptibility gene is that it cannot be coined normal or abnormal since its expression per se will not cause the disease. Environment-sensitive variants of these genes will reveal their impact only when the organism is subjected to the specific triggering environment. We will now present the basis of the genes $\times$ environment interactions (adapted from Lynch \& Walsh, 1997). Figure 2 shows the phenotypic response of 3 different variants of an environment-sensitive gene (called genotypes or alleles) in the presence of 2 different environments.

In Figure 2.a, the phenotypic response is enhanced in the presence of the $2^{\text {nd }}$ environment. This response, however, is identical for the 3 genotypes (the curves are parallel). In contrast, in figures 2.b, $c$ and $d$, the genetic variance is modified by environment ' 2 ', which is translated by an increase (Figure 2.b and c) or a decrease (Figure 2.d) in genetic variance between the 3 genotypes. In addition, the rank can be modified with the most sensitive genotype in one environment becoming the least sensitive in another environment (Figure 2.c and d). In all these 3 cases, the differential impact of the environment is allele-dependent. The increase in genetic variance observed with the environment ' 2 ' for figures $2 . b$ and $c$ is essential if one wants to unveil genetic susceptibilities. 


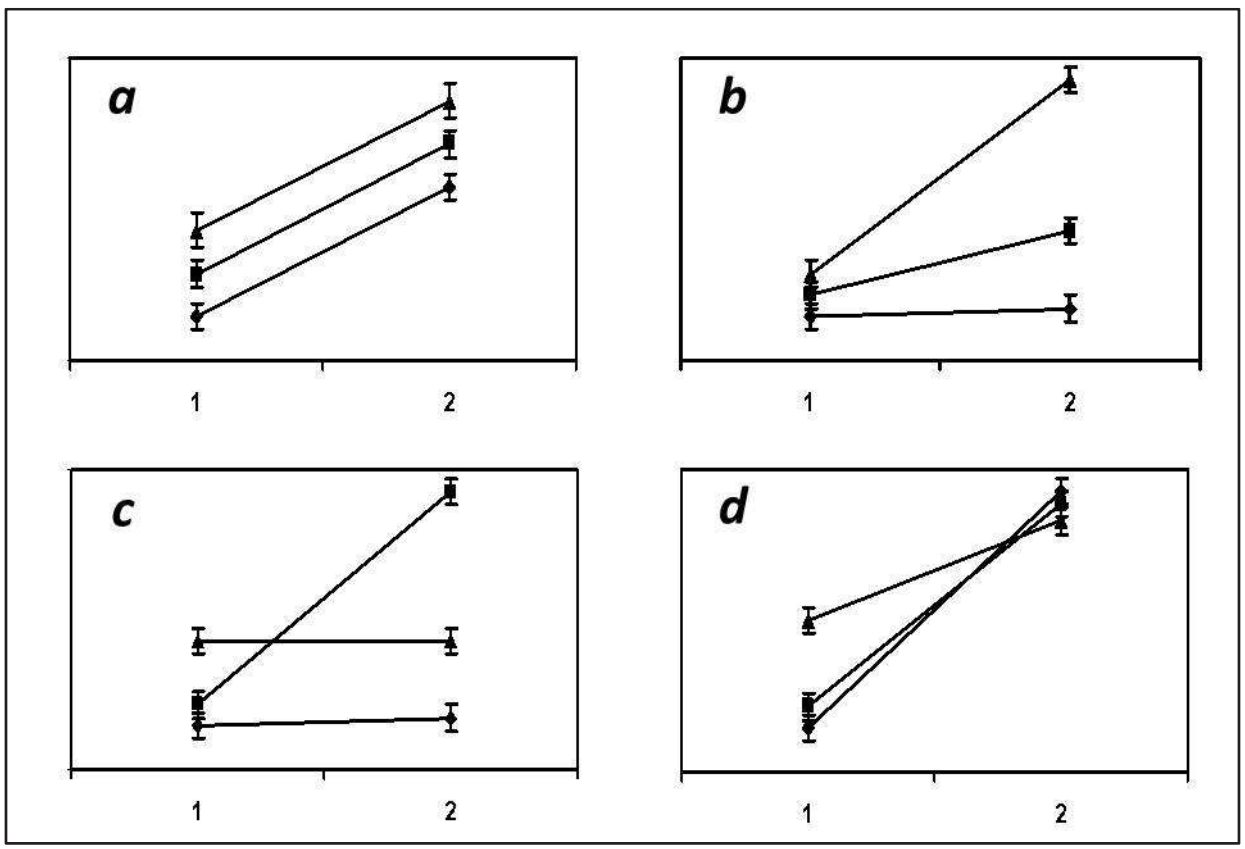

Fig. 2. Gene $\times$ environment interactions. Phenotypic expression of 3 different genotypes (alleles) when measured in 2 different environments (1, 2); adapted from Lynch \& Walsh, 1997.

It is important at this point to distinguish the impact of the environment that needs to be assessed for its contribution to the disease from the environmental variance that is the variance due to the measurements and is represented by the error bars on the graphs. For instance, in Figure 2, the genetic variance varies depending on the environment whereas the environmental variance does not change. The ratio of the genetic variance over the total variance (genetic + environmental variance) is called 'heritability' and the higher the heritability, the higher the contribution of genes to the studied trait. Technically, this means that when searching for genetic determinants of a disease, one should work with traits displaying a high heritability. However, heritability is not static, especially when considering susceptibility genes. As can be seen from Figure 2, while the environmental variability does not change (error bars), the genetic variance can be modified depending on the environment. Therefore, the key to study the contribution of susceptibility genes is to find the conditions where the genetic variance is at its maximum (for instance, Figure 2.b, environment 2). Because such conditions are not necessarily seen a priori in an experimental set-up, it is essential to challenge the model by changing the environment in which the trait of interest is measured. In hypertension research, that can be translated by the use of different diets or drugs in order to blow-up the differences in blood pressure and find the genes responsible for the differential effect.

This understanding is fundamental for selecting the parameters that will allow appreciating the influence of the environment in an experimental setting. This is the area where, we think, radiotelemetry can be the most useful in hypertension research. We will demonstrate later how the currently accepted methods for measuring blood pressure in animal models 
are not only adding artefacts and biases to the measurements, but how they are creating them because of their nature and the standard protocols employed.

\subsection{Stress as an important environmental modulator of hypertension}

We will now describe the genetic susceptibility to stress and its effects on blood pressure and hypertension development since it is among the most important environmental factor impacting hypertension (Hamet \& Tremblay, 2002). The concept of stress was first defined and described by Hans Selye (1956). He called it "the general adaptation syndrome" or G.A.S. It is defined by 3 phases: the alarm reaction, the resistance period and the exhaustion stage. He demonstrated the role of the sympathetic nervous system with the stimulation of the hypothalamic-pituitary-adrenal axis and the surge of the stress hormones cortisol and cathecholamines. While he was proposing that different stressors would always induce the same response, Henry (1992) showed that the neuroendocrine response is dependent on the perceived stress. For instance, when the stress is bearable, the response will be characterized by a secretion of noradrenalin. In contrast, when the stress persists and is overwhelming, a depressive state will appear. It is characterized by the strong stimulation of the pituitaryadrenal axis with intense secretion of cortisol and high levels of ACTH while the cathecholamines are unchanged. This, in turn, induces a sustained renin secretion, promoting a gradual and steady increase in blood pressure. When this increase is chronic, it leads to hypertension.

\subsection{Psychosocial stress and cardiovascular diseases}

Alexander (1939) suggested a link between emotional stress and the development of hypertension. For instance, people exposed to an ever changing environment see their blood pressure rise gradually (Gutmann \& Benson, 1971). The relationship between the stress of modern life and common diseases started to be more systematically assessed (Cobb \& Rose, 1973) and the Health Examination Survey (HES) and Health Examination and Nutrition Survey (HANES) allowed evaluating the link between the perceived stress at work with infarct prevalence. In 4,833 men enrolled in these studies, the results showed that job strain and absence of latitude and decisional power was perceived as a psychological stress that was significantly associated with an increased prevalence of infarct in this cohort (Karasek et al., 1988). A similar study on 2,556 men showed that the job strain was associated with increased prevalence of hypertension and left ventricular hypertrophy, a risk factor for infarct and cardiovascular diseases (Schnall et al., 1990). Data from the Framingham cohort showed that anxiety was predictive of a future hypertensive state in middle aged men followed for 20 years. This relationship was not verified in women however (Markovitz et al., 1993). There was therefore a need to better define psychosocial stress and standardize research protocols to draw reliable and reproducible results. More recent studies reported similar findings related to job stress with interactions with blood pressure-modulating genes (Ohlin B et al, 2008; Yu et al., 2008).

\subsection{Psychogenic stress}

It is well-recognized that stressful events such as wartime, natural disasters or more commonly hard living conditions are associated to a rise in arterial pressure in sufferers. A need for a test mimicking this perceived stress was necessary to characterize and understand the possible causal relationship between psychogenic stressors (i.e. from psychological origin) and the 
development of hypertension. The blood pressure response of two standardized tests correlated highly $(0,8)$ with the blood pressure at work (Morales-Ballejo et al., 1988). These standardized tests were a math test and a timed competitive video game test where subjects had to increase their score after each successfully reached levels. The strong correlation with "real-life" blood pressure made these tests good surrogates for everyday life stressors.

In addition to changes in blood pressure and heart rate, Anderson and colleagues (1987) showed a significant increase in blood flow in the arm of children from hypertensive parents during a math test, suggestive of changes in vascular resistance. Interestingly, physical exercise (isometric hand contractions) and math test in hypertensive were both able to increase circulating catecholamines and vasopressin but only the math test induced a rise in plasma renin and aldosterone levels (Sakamoto at al., 1992). For the authors, the activation of the renin-angiotensin-aldosterone system by this psychogenic test made the kidney a stress-sensitive target organ in susceptible hypertensive subjects.

\subsection{Enhanced stress response is predictive of hypertension - Concept of genetic susceptibility to stress}

The hemodynamic response to stressors is highly heritable (Hassan et al., 2009) and may help distinguish susceptible individuals. Falkner et al. (1979) observed an enhanced response of hemodynamic parameters in normotensive teens from hypertensive parents following a mental stress test. This enhanced response could predict who would become hypertensive later in life (Falkner et al., 1981). Normotensive men with a positive family history of hypertension showed an increased diastolic blood pressure after isometric handgrip testing when compared to controls without a family history of hypertension (Widgren et al., 1992). Similarly, the microcirculation response to local heat stress and skin blood flow is altered in normotensive with family history of hypertension (Gryglewska et al., 2010). In a cohort of adults and their children followed for six years, this increased response to stress was the strongest in the subjects found to display the highest diastolic and systolic blood pressure six years later. This was true in the adult and the boys, but not the girls of the cohort (Matthews et al., 1993). Maybe this sexual dimorphism reflected the young age of the children (20 years) at the end of the study. Presumably, the girls would be protected whereas their mothers (mean age, 48) would not be anymore because of menopause. Thus, the response to a psychogenic stress could be used as a tool to predict a future hypertension status in normotensive children with a positive family history of hypertension. In this case, blood pressure per se is not important; it is blood pressure in response to a specific change of environment (stress test) that proved to be the strongest marker. It comes back to what we tried to demonstrate earlier: the right question must be asked and the right measurements performed. Here, the change in environment (stress test) allowed revealing the genetic susceptibility (increase of genetic variance). If the enhanced response to stress can produce a transient or sustained increase in blood pressure as we have seen, it can also impact on the development of other cardiovascular pathologies. For instance, the hypersensitivity of the sympathetic nervous system has been proposed as a 'switch' responsible for the future decrease of cardiac function (Middlekauff et al., 1997), with endogenous catecholamines stimulating left ventricular hypertrophy. This has been shown in normotensive children of hypertensive parents (Trimarco et al., 1985). Thus, the continuous stimulation of the sympathetic nervous system by various stressors over a certain threshold could induce a rise in blood pressure and permanent changes in the cardiovascular system resulting in an irreversible hypertensive state (Capone et al., 2011; 
Thayer et al., 2010; Kuneš et al., 1990; Markel, 1985). Furthermore, genetic polymorphisms of tyrosine hydroxylase, the rate-limiting enzyme in catecholamines synthesis, are directly linked to the levels of the stress response (Rao et al., 2008). Thus, this neurogenic hypertension would result from the various environmental and genetic influences on the cardiovascular system. Therefore, the differential response to stress would define sensitive or resistant individuals. Because it is based on sensitivity genes, we call it the genetic susceptibility to stress.

In the previous paragraphs, we wanted to introduce this concept of genetic susceptibility to stress and insist on the fact that it is an essential component of hypertension development. Therefore, we think that it is not possible to study hypertension and the genetic basis of hypertension and ignore the impact of this environmental component. The rest of our review will demonstrate the essential role of telemetry in hypertension research in monitoring and dissecting this component, a goal that was impossible to achieve before the advent of telemetric measurement of blood pressure.

\section{Animal models in hypertension research}

Animals were first studied to understand normal physiology, especially when necropsy on human beings was forbidden by the Church. Soon, it became evident that animals could suffer from most of the same ailments as humans. It then became natural to study diseases in animals in order to draw parallels with the human disease counterpart and test treatments. With the discovery of the laws of genetics by Mendel and their re-discovery at the beginning of the 20 th century, the breeding of animals for selection of desired traits had now a scientific basis. At that time, mice were very popular as pets and breeders rivalled to produce strains with unique and "desirable" aesthetic characteristics. In order to perpetuate these characteristics in the next generations, brother-sister mating was performed over several generations. This gave rise to the first inbred lines, many of them still available today. The reader can refer to Beck et al. (2000) for a complete review. This massive breeding of mice by amateur breeders and scientists gave also rise to surprising discoveries: animals that were plagued with genetic ailments. Because the strains were inbred, the study of the disease was then possible on multiple animals displaying the same phenotype and over time. It was the beginning of modern biological science. Mice are very good genetic models of diseases, but rats were always the preferred model for physiology because of their "practical size". For organ size, blood drawing and any kind of measurements, rats provide more "research material", are bigger, sturdier, and, not the least, less aggressive than mice. This explains why the rat and mostly the Spontaneously Hypertensive Rat (SHR) is the animal model for hypertension research. The SHR was developed by Okamoto and Aoki (1963) by selective breeding of hypertensive males and females from their Wistar colony. The original inbred strain was then distributed to the NIH and institutes around the world. Because of this world-wide distribution, the SHR became the most popular animal model for the study of hypertension. The drawback of this popularity and wide distribution is that several substrains were generated since 1962, either by breeding errors or simply due to genetic drift. For instance, a vendor, Taconic Farms, has a salt-sensitive substrain of SHR (SHR-S) available from its IBU-3 colony (Mozaffari et al., 1991). This sole example simply to illustrate that, even within the same strain, there can be significant genetic differences impacting the studied phenotype. Furthermore, this example of salt-sensitivity illustrates an environmental susceptibility not usually present in SHR. As a result, researchers should be aware of the heterozygosity of the strain and be able to monitor the differential impact of 
salt or it may go unnoticed and create bias in analysis and results inconsistencies. Other rat inbred strains were developed for the study of hypertension. We will not go into details as it is not the goal of this chapter, but we should not forget to mention the Dahl salt-sensitive and salt-resistant rat and the Milan hypertensive rat among the most popular models. For review, please see Bader (2010). With the advent of these models and the sequencing of the rat genome, discoveries in the rat can be directly verified in humans, and several quantitative trait loci mapped on the rat genome were also described in humans. The review of Stoll and Jacob (2001) about rat models of hypertension and their relationship to human hypertension is suggested as well as the review of Kwitek et al. (2001) for a description and usage of the synteny between rat, human and mouse genomes.

\subsection{Animal models to study the stress response}

Several animal models can be used to study the stress response and the choice is dependent on the stressor to be employed and the expected outcomes. For instance, chronic immobilisation of the arm for a period of 15 months induced a gradual rise in blood pressure in monkeys (Kuneš et al., 1990). This hypertensive state persisted even when the animals were freed from that restraint and was observed in conscious or anaesthetized monkeys. For short-term and more ethically-acceptable studies, rats are the model of choice. Several stressors can induce hypertension: introduction of an intruder into the cage (Mitra et al., 2011), conflictual situation like food consumption followed by an electric shock (Friedman \& Dahl, 1977), cold stress applied to the floor of the cage (Kanayama et al., 1979) and a psychogenic stress, immobilisation (Kvetnansky et al., 1970). Interestingly, in the SHR, immobilisation will induce a rise in blood pressure to levels higher than what is observed in normotensive WKY rats (Grundt et al., 2009; Yamori et al., 1969). McMurtry and Wexler (1981) have shown that ether, heat and immobilisation induce an increase of several biochemical markers of the stress response, with the SHR being more sensitive than the Sprague-Dawley control. SHR was then considered a model of 'neurogenic' hypertension similar to what is seen in humans (Folkow, 1982). Therefore, this hypersensitivity to stress found in SHR and also in hypertensive mice (Davern et al., 2010) may be involved in the development of hypertension by lowering the threshold at which a stimulus is perceived as a real stress. The higher stress response resulting can affect several pathways and organs and will contribute to the development of hypertension. Of note, the stress gene expression is enhanced in SHR as compared to WKY and Brown-Norway rats after a 1-hour immobilisation stress, and the genetic difference points to the heat-shock transcription factor hstf (Dumas et al., 2000a \& 2000b). Others have reported differences in blood flow or increase in sympathetic nerve activity associated with sodium retention in SHR following stress (Yamamoto et al., 1987; Koepke \& DiBona, 1985). All these genes and mechanisms can be involved in the development of hypertension.

In conclusion, hypertension research is performed mostly on the SHR rat, an animal that was bred for its spontaneous hypertension. We now know that the various colonies kept by vendors or institutions around the world do present some important genetic differences, several of them impacting blood pressure and hypertension development. Furthermore, SHR is a stress-sensitive model that mimics neurogenic hypertension. Therefore, because this hypersensitivity to stress and genetic differences pertaining to salt-sensitivity may impact the development of hypertension in SHR, it seems essential to study these environmental susceptibilities when studying hypertension in SHR or, to the least, be aware of these confounders in blood pressure measurements and data analysis. This is where telemetric measurement of blood pressure could be a very useful tool. 


\section{Blood pressure measurement in mouse and rat}

An essential requirement for hypertension research in animal models is the ability to reliably and accurately monitor blood pressure and its slight variations in unanaesthetized conscious animals. The choice of a research methodology and the techniques to be used will be dependent on the specific research goals. Thus, a given method for measuring blood pressure may be well suited for one type of study and not recommended or useful for another. Furthermore, the more expensive and technologically-advanced technique is not necessary the best to employ. For instance, if there is a need to monitor rapid changes in blood pressure consecutive to the intravenous injection of a test compound, telemetry is most suitable because it can record almost instantly the changes in blood pressure. This is particularly true for fast and short-acting substances. Inversely, if one wants to study the changes in target organs consecutive to a long-term treatment with a new vasoactive drug, a sole determination close to the end of the treatment with a non-invasive and 'coarse' method such as tail-cuff should be enough to assess if the test article behaved as expected in the treated animals. We will now review the methods for blood pressure measurement in rodents with an emphasis on the most commonly used technique, the indirect tail-cuff method, and the state-of the art non-invasive telemetric method. Again, the interested readers will be directed to the review by Kurtz et al. (2005), Zhao et al. (2011) or Feng \& DiPetrillo (2009) for details and information on other methods.

Ruban D. Buñag started his 1983 review of blood pressure measurement techniques in rats by "A rat's tail is a slender appendage on which the weight of so much research in hypertension hangs, yet blood pressure measurements recorded from it are usually taken for granted, often abused, but seldom discussed» (Buñag RD, 1983). This is the commentary of someone who had first-hand experience of the available techniques for blood pressure determination in animal models of hypertension. At that time, the only available techniques were direct puncture of an artery under light anaesthesia (usually the carotid artery) or the indirect tail-cuff method.

\subsection{Indirect method in conscious rodents: The tail-cuff method (Williams et al., 1939)}

Often cited as «the tail-cuff method» without further details, this method is an adaptation of the indirect method used in humans. In humans, physicians wrap a cuff around the arm of the patient. With the stethoscope, they can hear the heartbeats while deflating the cuff (Korotkoff sounds). When done correctly, the beats are audible only when the cuff pressure is smaller than the systolic pressure or higher than the diastolic pressure. Thus, these limits represent respectively the systolic and diastolic values of blood pressure of the individual. In order to achieve the measurement, one needs an artery (here, the brachial artery), a cuff to squeeze the artery and interrupt the blood flow and a device to perceive and monitor the blood flow during inflation and deflation (the stethoscope). This key technique to many diagnostic procedures is performed everyday by physicians in their offices and in the hospitals around the world. Its ease of use and the knowledge it brings to assess the condition of the patients makes it probably one of the most important techniques available to physician, even in the era of computers and scanners. The ease of use of the indirect blood pressure determination in humans comes mostly from the fact that the blood pressure determination is performed in conscious subjects and uses a non-invasive procedure on the arm.

How can it be adapted to rodent models of hypertension? In a straightforward adaptation in the animals, researchers considered using the tail in rats and mice as the «organ» around 
which a cuff could be wrapped (limbs can be employed for bigger animals such as dogs), hence the name «tail-cuff method». In a mouse, the tail is irrigated by one ventral artery and 2 lateral caudal veins. The rats possess the same vascular architecture with the addition of a dorsal vein. Therefore, the cuff squeezes the tail to a pressure greater than systolic pressure, and a sensor distal to the cuff is placed to detect the return of the blood flow as the cuff is deflated. Several sensors are available on the market, with some more sensitive than others. In all cases however, only the systolic blood pressure can be perceived with this method. Furthermore, because the only tail artery is on the ventral side, positioning of the sensor is critical to get a good signal. The strength of the signal is also dependent on the position of the cuff and sensor on the tail: the closest to the animal (proximal), the better the signal. Therefore, one can imagine that the size of the cuff must be adapted to the size of the tail, and the position of the cuff must be standardized, at least within the same experiment. To our knowledge, these precautions are rarely mentioned as most authors will only say "blood pressure was performed as previously mentioned" without further details. But these are the least of the culprits that are impacting the measurement with the tail-cuff method. In the light of what we have presented, we will put the emphasis on a major issue responsible for most problems and artefacts: the mandatory use of restraint cages in order to be able to perform this fine tuning on conscious animals. For a detailed depiction of all the other pitfalls of the tail-cuff method, please refer to Buñag (1983).

\section{Recommended for non-invasive detection or screening of:}

Frank systolic hypertension

Substantial group differences in systolic blood pressure

Substantial changes in systolic blood pressure over time

High-throughput screening of large numbers of animals when

large differences in blood pressure are expected

\section{Not recommended for:}

Assessing small differences in blood pressure

Quantifying relationships between blood pressure and other variables

Studying blood pressure-independent effects of any intervention Measuring blood pressure variability

Measuring diastolic or pulse pressure

Measuring blood pressure in conscious rodents

Measuring blood pressure in stress-sensitive animals

Monitoring possible hemodynamic effects from rapid and shortacting substances

Table 2. Recommendations for the use of indirect methods for measuring blood pressure in animals (adapted from Kurtz et al., 2005)

\subsubsection{Effect of restraint on blood pressure determination: Increase in cardiovascular response and in body temperature}

In order to be able to install the cuff and record blood pressure, mice and rats are put in restrainers with the tail hanging out. As we have shown at paragraph 4.2, immobilisation 
stress is considered a psychogenic stress. In the rat, it induces a rapid increase in heart rate and blood pressure, and it has been shown that this increase is higher in SHR when compared to normotensive controls (Yamori et al., 1969; Irvine et al., 1997). Immobilisation also induces an increase in body temperature in the rat (Gollnick \& Iannuzzo, 1968; Briese \& De Quijada, 1970; Stewart \& Eikelboom, 1979; Singer et al., 1986), in the mouse and in the rabbit (Snow \& Horita, 1982). In humans, psychogenic stressors also induce a rise in body temperature in addition to the rise of blood pressure and heart rate (Marazziti et al., 1992). The rise in body temperature induced by immobilisation is also stronger in SHR than in normotensive WKY (Berkey et al., 1990, Morley et al., 1990). At room temperature, nonstressed body temperature has been shown to be identical (Berkey et al., 1990) or higher in SHR as compared to WKY (Price \& Wilmoth 1990). Wilson at al. (1977) indeed suggested that the basal temperature threshold of SHR is modified, thus explaining its abnormal temperature response to stress. Price and Wilmoth (1990) reported a higher vascular sensitivity to norepinephrine in SHR and O'Leary and Wang (1994) showed a decreased vasodilation in the tail vessels in SHR. Together, these 2 mechanisms could explain the higher temperature reached during immobilisation stress and the inability to go back to baseline rapidly after the stress. Therefore, the stronger temperature response to immobilization in SHR could serve as a marker of stress susceptibility. Indeed, we have found the genetic determinants of this enhanced stress response in hypertensive rats and observed a strong sexual dimorphism in the SHR, the $\mathrm{Y}$ chromosome from hypertensive origin contributing significantly to this enhanced response (Dumas et al., 2000a). Because a similar abnormal response has also been reported in humans subjected to psychogenic stress, and because this abnormal response correlates with the future hypertensive status of these individuals, it is important 1) to characterize and to be able to recognize this stress response and 2) to employ methods of blood pressure determination devoid of this important confounder.

\subsubsection{Effect of heating on blood pressure determination}

In rodents, there are 3 veins and one artery in the tail. However, because its length usually equals that of the body in mouse and rats, most of the time, no blood is flowing through these vessels because of the heat-loss that would result. Hence, the tail serves mainly for thermoregulation. Therefore, when attempting to determine blood pressure with the tailcuff method, in addition to the restrainer, heating of the animal to temperatures between 30 and $37^{\circ} \mathrm{C}$ is mandatory in order to get a significant blood flow into the tail. This heat stress thus adds to the body temperature increase due to stress and some animals may die even with prior training to the experimental conditions (Gross \& Luft, 2003).

\subsubsection{Thermosensitivity and hypertension}

Schlager (1974) have reported a higher heat sensitivity in the spontaneously hypertensive mouse (SHM) mice as compared to controls. SHR also presents an increased thermosensitivity (Wilson et al., 1977; Wright et al., 1978; McMurtry \& Wexler, 1983). This thermosensitivity persists in culture and is already present in neonatal cardiomyocytes, indicatives of a primary genetic defect not consecutive to high blood pressure (Hamet et al., 1985). Malo from our group (1989) has unveiled the existence of the thermosensitivity locus tms associated with hypertension in SHM. When anaesthetized SHM mice were immersed in a $44^{\circ} \mathrm{C}$ water bath, their body temperature increase was faster $\left(1,74+/-0,04^{\circ} \mathrm{C}\right.$ versus $1,13+/-0,03^{\circ} \mathrm{C}$ degree per minute, $\mathrm{p}<0,001)$ and their survival decreased when compared to control mice. This was 
indicative of a defect in temperature regulation in this strain. When subjected to a 5-min conditioning at a non-lethal $40^{\circ} \mathrm{C}$ temperature for 20 consecutive days, SHM mice exhibited a $20 \mathrm{~mm} \mathrm{Hg}$ lower blood pressure as compared to non-treated SHM, and this effect was reversed upon the interruption of this pre-conditioning (Malo et al., 1990).

\subsubsection{Seasonal temperature and the development of cardiovascular diseases}

It is interesting to note that seasonal temperature itself has an impact on mortality and incidence of cardiovascular diseases. For instance, it is known for a long time that there is an inverse relationship between outside average temperature and blood pressure levels (Rose, 1961; Hata et al., 1982). In Montreal (Canada), where outside temperature varies from $-24^{\circ} \mathrm{C}$ to $27^{\circ} \mathrm{C}$ on a yearly average, a study on 2,000 patients with a total of 42,813 blood pressure readings showed a significant inverse relationship between blood pressure and average outside temperature (Kuneš et al., 1991). More recently, a $1^{\circ} \mathrm{C}$ reduction in daily mean temperature was associated with a $2 \%$ cumulative increase in risk of myocardial infarction over the current and following month, with the strongest effects observed after lags of 1 and 2 weeks (Bhaskaran et al., 2010). In many countries, death rates in winter are 10-25\% higher as compared to the rest of the year (Curwen, 1991). When corrected for confounders, only temperature showed a constant correlation strongly suggestive of causality. Therefore, stressors that are impacting body temperature should not be seen merely as a side effect of immobilisation. We do think that these must be taken into account when measuring blood pressure and techniques for blood pressure determination that are minimizing stress and its manifestation must be favoured.

\subsubsection{Conditioning to restraint stress}

It was recognized that restraining is stressful and it has been proposed that seven days of training to the procedure would alleviate the effect of stress and enable the measurements of 'usual' blood pressure in the animals. The idea is the animals would get used to the restrainer and to the manipulation of their tails and display less stress-induced changes in their cardiovascular parameters following conditioning. Gross and Luft (2003) have shown that this conditioning period had no effect in mice. With mice implanted with telemetry transmitters, they have shown that heart rate, systolic and diastolic blood pressure at day 1 was not different than after 10 days of 30-minutes conditioning in the restrainers. A similar absence of conditioning was previously reported for rats (Bazil et al., 1993; Irvine et al., 1997).

This clearly demonstrates that immobilization of rodents in order to measure blood pressure will induce significant artefacts, that training does not prevent these bias and can further modulate the blood pressure in ways not consistent with what is sought. Furthermore, because the stress sensitivity may differ between strains, subtle differences in blood pressure may be missed. Finally, as we have seen, the different thermosensitivity of various strains of rodents in addition to the blood pressure-modulating effect of heat are two significant confounders that could ruin an experimental protocol. Hence, we think that the tail-cuff blood pressure method' can only be used when large blood-pressure differences $(>=15-20$ $\mathrm{mm} \mathrm{Hg}$ ) are expected in the experimental setting when the restrainer effects become minor as compared to the effects of the tested hypothesis.

\subsection{Direct non-invasive method: Radiotelemetry}

Radiotelemetry for blood pressure monitoring in animals requires the surgical implantation of a catheter in a suitable artery, usually the carotid or femoral artery. The transmitter itself 
is inserted in the abdominal cavity (for rats) or under the skin (for mice). Interestingly, with the miniaturization of electronic components and probably because of the pressure of animal rights activists, there has been an impressive decrease in the number of publications using telemetry in large animals (cats, dogs, swine, monkeys) and a significant increase in those employing rodents (Kramer et al., 2001). Our own experience is with the transmitters from Data Sciences International (DSI, St-Paul, MN, USA), but other manufacturers are present on the market. For a review of the progress in radiotelemetry in small animals, please refer to Kramer et al. (2001). Similarly, the interested reader can consult the original publication by Mills et al. (2000) describing the characteristics of the mouse transmitters from DSI as well as the review article by Huetteman \& Bogie (2009) that describes in details the surgical procedures to implant DSI transmitters in rats and mice.

Because of the surgery needed for the installation of the transmitters, radiotelemetry can be considered an invasive technique. But, at the same time, when recovery from surgery is optimal, it is the least invasive method since the measurements are achieved in the usual environment without external stressors such as the direct intervention of the technician. Furthermore, measurements are performed not only on undisturbed animals, but also in freely moving animals, which contrasts with all the other measurement techniques. Indwelling catheters attached to tethering devices is the only method allowing some movement of the conscious animals but generates noise and stress and does not come close to what can be achieved by telemetry. Blood pressure can be performed continuously on a beat-to-beat basis and during the night, a period not always practical for the experimenter. It allows the monitoring of the circadian rhythm impact and greatly reduces the variation in the mean blood pressure when data are averaged over several hours. For instance, Van Vliet (2003) has shown that the $95 \%$ confidence interval of the mean of 24 hours of blood pressure measurements in a group of 9 mice was $8 \mathrm{~mm} \mathrm{Hg}$ as compared to $14 \mathrm{~mm} \mathrm{Hg}$ for 30-minutes average and $22 \mathrm{~mm} \mathrm{Hg}$ for a single time point. In SHR, systolic blood pressure is $20-40 \mathrm{~mm}$ $\mathrm{Hg}$ higher and heart rate $100 \mathrm{bpm}$ faster when assessed by tail-cuff or directly by indwelling catheters (Bazil et al., 1993). In mice, while the tail cuff results are highly correlated with direct arterial pressure $(\mathrm{r}=0,86, \mathrm{p}<0,01)$, the tail-cuff values are $20 \mathrm{~mm} \mathrm{Hg}$ higher on average (Krege et al., 1995). For both species, the lowest blood pressure values are obtained with implantable radiotelemetry because the method is devoid of stress and performed in freely moving animals without anaesthesia (Irvine et al., 1997; Mills et al., 2000; Kuneš et al., 2008).

\section{Recommended for:}

Measuring blood pressure in conscious unrestrained animals

Measuring blood pressure continuously over time

Measuring blood pressure variability

Quantifying hypertension or changes in blood pressure

Quantifying relationship between blood pressure and other variables

Studying blood pressure-dependent and independent effects following interventions

Table 3. Recommendations for the use of telemetry for measuring blood pressure in animals (adapted from Kurtz et al., 2005).

Table 3 summarizes the recommended use and advantages that apply to direct blood pressure measurements methods and especially to telemetry. The only application for which the AHA indicates that direct methods are not recommended is for screening of large 
number of animals and/or when large blood pressure effects are expected. The reasons why these methods are not recommended are their cost and the technical skills that are required to perform them successfully and reproducibly. They are, however far superior scientifically.

\section{Radiotelemetry to study gene $x$ environment in hypertension - Experience from our laboratory}

Hypertension is an important contributor of mortality and morbidity in humans. Our understanding of the aetiology of the disease is incomplete and the search for the genetic determinants is complicated by the fact that blood pressure is very labile, with important changes occurring within seconds and minutes. As we have shown, blood pressure is hard to assess reproducibly without bias when performing epidemiological studies or GWAS. These problems are in part due to the important environmental component modulating blood pressure. Among these environmental modulators, psychogenic stress exerts a major influence. In experimental research using rodents, we have shown that the usual tail-cuff method for blood pressure determination induces stress and increases body temperature, two major modulators of blood pressure and hypertension. Therefore, we think that telemetry is the only technique to ascertain blood pressure with the least amount of bias. It is also the only technique allowing the measurement of the stress component modulating blood pressure. The few examples below will try to illustrate the level of refinement and robustness that can be achieved in hypertension research when the environmental influences are understood and telemetry the method employed for assessing blood pressure.

\subsection{Diet and stress modulation of hypertension}

The work by Šedová et al. (2004) from our group illustrates the various concepts that we have presented here and take advantage of telemetric measurement of blood pressure to draw conclusions that would have been impossible to obtain otherwise. The manuscript describes the effects of diet-induced obesity in the SHR. Because the cardiovascular response to stress is a significant predictor of hypertension, it looked more specifically at the effects of the diet on the stress response and the global impact on cardiovascular morbidity. In order to do so, adult male SHR were fed a high fat diet for 12 weeks. Blood pressure and heart rate were measured by telemetry at week 0 and week 12 . In addition to basal blood pressure recorded for 3 consecutive days each time, blood pressure determination in response to a 30minutes immobilisation stress was also performed at weeks 0 and 12 .

As expected, immobilisation stress in restrainers for 30 minutes was able to increase blood pressure and heart rate in both groups. While there was no difference in the blood pressure response to stress in both groups between week 0 and 12, there was a significant lag in the return to the baseline after stress in the high-fat diet group at week 12 as compared to week 0 . This was significant for systolic and diastolic blood pressure as well as for heart rate. No difference was observed in the response to stress in the control animals in the stress or poststress periods. Furthermore, because it allowed the measurement of the circadian pattern of blood pressure, telemetry could reveal a blood pressure increase during the night in the animals receiving the high-fat diet as compared to the normal-chow fed controls. As we have seen from the immobilisation stress data, this would have been impossible to detect with a one-time recording in stressful conditions by the tail-cuff method. Needless to say, measuring blood pressure during stress and after stress with any other techniques could not 
have yielded such results. We think that telemetry is the most appropriate mean for measuring blood pressure in this kind of work involving the modulation of blood pressure by environmental stressors. We also want to underline the fact that stress is always present when dealing with blood pressure measurements in rodents. Given its impact on blood pressure, it has to be taken into consideration even when it is not specifically under study.

This example is a good illustration of the study of the gene $\times$ environment interactions: We had to increase the genetic variance in order to be able to monitor changes that would not be visible otherwise. The first challenge was the use of an obesity-inducing diet that revealed differences in blood pressure response to stress and in the night period of the circadian pattern. The second challenge was the stress test where we could observe a delay in the return to the baseline in the high-fat diet treated rats. This is very interesting in the light of another finding: an augmentation of the cardiac mass in the rats fed a high fat diet. With the telemetric data, we can hypothesize that the increase in cardiovascular reactivity observed in the night (active period of the rats) and following a stress could explain an increased workload for the heart and the hypertrophy after only 12 weeks of high-fat diet. The effect of the diet would thus be more important when the animals are awake, active and experiencing daily stressors. This interpretation would be impossible without the telemetric data.

\subsection{Genetic determinants of emotionality and stress response in mice}

Some strains of mice such as the A/J strain display high anxiety levels. The A/J and C57Bl6 strains are the progenitors of the recombinant congenic strains $\mathrm{AcB} / \mathrm{BcA}$. With the help of this recombinant congenic strains panel, Thifault et al. (2008) unveiled quantitative trait loci of the stress response and of emotionality in mice. For the stress response, a 30-minute immobilisation stress was carried out. In these mice, it is characterized by two phases: initial hypothermia followed by thermogenesis. For emotionality, open-field test (number of fecal boli) and elevated plus maze (enclosed arm duration and emergence latencies) were employed. The results unveiled several genomic loci associated with the differential response in the recombinant congenic strains panel. Of major interest, stress loci overlapped with candidate loci for cardiovascular diseases. For instance, the BcA70 strain showed a down regulation of the Atp1a2 gene in the heart and brain as compared with the parental C57Bl6 strain $(\mathrm{p}<0,001$ and $\mathrm{p}<0,05$, respectively), and this is in accordance with the high emotionality of the knock-outs for that gene and its involvement in salt-sensitive hypertension.

These remarkable data, resulting from complex analysis of genomic and phenotypic results would not have been possible without telemetry. The body temperature recordings from the stress test were performed with the telemetry implants and a strain distribution pattern over $2,5^{\circ} \mathrm{C}$ was obtained and could be used to unveil significant loci associated. This temperature difference could not have been monitored with precision with any other means. As for blood pressure, telemetry allowed the monitoring of body temperature continuously and the circadian pattern was obtained. It showed a significant strain $x$ diet effect with the AcB strains (mostly A/J background) displaying a lower body temperature under high-salt diet, and the strain differences were steeper during the dark phase of the circadian cycle. Again, these subtle observations would not have been possible without continuous monitoring by telemetry.

This study unveiled genetic loci responsible for the differential responses to many of the stressors and tests performed. Since it is easy to get spurious association with genetic 
markers, good phenotyping is essential if one wants to rely on the results. Given the important consequences if one wants to pursue the study of a candidate locus, we think that telemetry is essential for quality phenotyping in genetic research.

\subsection{Dissection of hypertension: Positional cloning of quantitative trait loci for blood pressure}

Finally, we should not forget to mention the work from Alan Deng who dissects hypertension in the rat and was able to find several significant blood pressure quantitative trait loci (Deng, 2007). His systematic approach uses telemetry as the sole method for blood pressure determination. The blood pressure values are obtained from adult rats from inbred strains. He does, however, perform several genetic manipulations in order to be able to reveal the loci. This approach allowed him to report several loci, the chromosomal position of which are later refined by producing sub-congenics animals (Chauvet et al., 2008). He was also able to reveal some gene-diet interactions and gene-gene interactions. For instance, he was able to demonstrate that a minor effect locus (named C18QTL1) could exert a major effect when it was transferred onto another genetic background. The normotensive Lewis rat genetic background was preventing this locus from exerting its full effect (Charron et al., 2005). This indicates that the normotensives also possess high blood pressure genes, but their effects are counterbalanced by 'normotensive' genes. This demonstrates the genetic buffering capacity of the genome and probably explains why the GWAS performed in humans do not yield the desired major high blood pressure loci: the population are displaying genetic heterogeneities that dilute the loci effects.

\section{General conclusion}

In this review, we have tried to demonstrate the importance of the environmental component of hypertension. When recognizing this importance, we think that it becomes easier to select the right tools to measure blood pressure in animal models as well as in humans. Human studies tend to indicate a decrease of the prevalence of hypertension whereas it may only be the reflection of the new standardized methods for the measurement of blood pressure devoid of stress. We have shown that rodents used for hypertension research are also stress sensitive and that the most commonly used method for blood pressure determination exacerbates the stress perceived by the animals: it increases blood pressure and body temperature. Since we have presented evidences indicating that stress and temperature can in turn be involved in the development of hypertension, it seems essential to subtract their influence when studying hypertension. Therefore, we think that telemetry is the sole method to perform blood pressure measurement in animal models of hypertension because it enables to subtract the stress artefacts or, conversely, to study them. Furthermore, no genetic studies should be performed in animals if telemetry is not used to characterize the blood pressure levels. Some differences are small and inadequate phenotyping could ruin a GWAS by revealing spurious statistical associations and diverting researchers to wrong candidate genes. On the other side, in an effort to standardize the techniques and eliminating human interference and bias, human epidemiological and genetic studies tend to eliminate the stress component from the measurement of blood pressure. As we have shown, this approach is desired in animal studies especially because we are dealing with inbred strains and can test our hypothesis is several backgrounds. Small effect blood pressure loci have more chance of being 'true' and can be verified in congenics 
in several backgrounds. Paradoxically, in human research, we think that reducing stress results in narrowing the range of available blood pressure (decrease of genetic variance). It may thus explain why no major blood pressure loci were found despite the increased size of the study populations in recent studies. Maybe this is a mistake and, because of the genome buffering, none of the hypertensive genes would ever manifest themselves in such conditions. Therefore, we do think that telemetry is the State-of-the-Art method for blood pressure determination. But, first, we think that the right question must be asked before any blood pressure determination attempt. Only with well-defined goals and phenotype will a blood pressure method easy to select and the results obtained valid and reproducible. It is especially true if one wants to find "high blood pressure" genes (Korner, 2010).

\section{References}

Alexander F 1939. Emotional factors in essential hypertension. Presentation of a tentative hypothesis. Psychosom Med;1:173-179.

Anderson EA, Mahoney LT, Lauer RM \& Clarke WR. Enhanced forearm blood flow during mental stress in children of hypertensive parents. Hypertension;10:544-549.

Bader M 2010. Rat models of cardiovascular diseases. Methods Mol Biol;597:403-414.

Baskaran K, Hajat S, Haines A, Herrett E, Wilkinson P \& Smeeth L 2010. Short term effects of temperature on risk of myocardial infarction in England and Wales: time series regression analysis of the Myocardial Ischaemia Natonal Audit Project (MINAP) registry. BMJ;341:c3823.

Bazil MK, Krulan C \& Webb RL 1993. Telemetric monitoring of cardiovascular parameters in conscious spontaneously hypertensive rats. J Cardiovasc Pharmacol;22:897-905.

Beck JA, Lloyd S, Hafezparast M, Lennon-Pierce M, Eppig JT, Festing MF \& Fisher EM 2000. Genealogies of mouse inbred strains. Nat Genet;24(1):23-25.

Berkey DL, Meeuwsen KW \& Barney CC 1990. Measurement of core temperature in spontaneously hypertensive rats by radiotelemetry. Am J Physiol;258:R743-R749.

Briese E \& De Quijada MG 1970. Colonic temperature of rats during handling. Acta Physiol Latinoam;20:97-102.

Brown MA, Davis GK \& McHugh L 2001. The prevalence and clinical significance of nocturnal hypertension in pregnancy. J Hypertens;19:1437-1444.

Buñag RD 1983. Facts and fallacies about measuring blood pressure in rats. Clin Exp Hypertens;A5(10):1659-1681.

Campbell NR, So L, Amankwah E, Quan H, Maxwell C \& Canadian Hypertension Education Program Outcomes Research Task Force 2008. Characteristics of hypertensive Canadians not receiving drug therapy. Can J Cardiol;24(6):485-490.

Campbell NR, Brant R, Johansen H, Walker RL, Wielgosz A, Onysko J, Gao RN, Sambell C, Phillips S, McAlister FA \& Canadian Hypertension Education Program Outcomes Research Task Force 2009. Increases in antihypertensive prescriptions and reductions in cardiovascular events in Canada. Hypertension;53:128-134.

Capone C, Faraco G, Park L, Cao X, Davisson RL \& Iadecola C 2011. The cerebrovascular dysfunction induced by slow pressor doses of angiotensin II precedes the development of hypertension. Am J Physiol Heart Circ Physiol;300(1):H397-H407.

Charron S, Lambert R, Eliopoulos V, Duong C, Ménard A, Roy J \& Deng AY 2005. A loss of genome buffering capacity of Dahl salt-sensitive model modulate blood pressure as a cause of hypertension. Hum Mol Genet;14(24)3877-3884. 
Chauvet C, Charron S, Ménard A, Xiao C, Roy J \& Deng AY 2008. Submegabase resolution of epistatically quantitative trait loci for blood pressure applicable for essential hypertension. J Hypertens;26(5):893-901.

Cobb M \& Rose RM 1973. Hypertension, peptic ulcer, and diabetes in air traffic controllers. JAMA;224:489-492.

Curwen M 1991. Winter mortality: a British phenomenon? Health Trends;22:169-175.

Davern PJ, Jackson KL, Nguyen-Huu TP, La Greca L \& Head GA 2010. Cardiovascular responses to aversive and nonaversive stressors in Schlager genetically hypertensive mice. Am J Hypertens;23(8):838-844.

Deng AY 2007. Positional cloning of quantitative trait loci for blood pressure: How close are we? A critical perspective. Hypertension;49:740-747.

Dominiczak AF \& Munroe PB 2010. Genome-wide association studies will unlock the genetic basis of hypertension. Pro side of the argument. Hypertension;56:1017-1020.

Dumas P, Pausova Z, Kren V, Krenova D, Pravenec M, Dumont M, Ely D, Turner M, Sun Y, Tremblay J \& Hamet P 2000a. Contribution of autosomal loci and the $Y$ chromosome to the stress response in rats. Hypertension;35:568-573.

Dumas P, Sun Y, Corbeil G, Tremblay S, Pausova Z, Kren V, Krenova D, Pravenec M, Hamet P \& Tremblay J 2000b. Mapping of the quantitative trait loci (QTL) of differential stress gene expression in rat recombinant inbred strains. J Hypertens;18:545-551.

Falkner B, Onesti G, Angelakos ET, Fernandes M \& Langman C 1979. Cardiovascular response to mental stress in normal adolescents with hypertensive parents: Hemodynamics and mental stress in adolescents. Hypertension;1:23-30.

Falkner B, Kushner H, Onesti G \& Angelakos ET 1981. Cardiovascular characteristics in adolescents who develop essential hypertension. Hypertension;3:521-527.

Feng M \& DiPetrillo K 2009. Non-invasive blood pressure measurement in mice. Methods Mol Biol;573:45-55.

Folkow B 1982. Physiological aspects of primary hypertension. Physiol Rev;62:347-504.

Friedman R \& Dahl LK 1977. Psychic and genetic factors in the etiology of hypertension. In Stress and the heart. D Wheatley Ed, pp. 137-156. Raven Press, ISBN- 0890041512, New York.

Gollnick PD \& Iannuzzo CD 1968. Colonic temperature response of rats during exercise. J Appl Physiol;24:747-750.

Gross V \& Luft FC 2003. Exercising restraint in measuring blood pressure in conscious mice. Hypertension; $41: 879-881$.

Grundt A, Grundt C, Gorbey S, Thomas MA \& Lemmer B 2009. Strain-dependent differences of restraint stress-induced hypertension in WKY and SHR. Physiol Behav;97:341-346.

Gryglewska B, Necki M, Cwynar M, Baron T \& Grodzicki T 2010. Local heat stress and skin blood flowmotion in subjects with familial predisposition or newly diagnosed hypertension. Blood Press;19(6):366-372.

Gutmann MC \& Benson A 1971. Interaction of environmental factors and systemic blood pressure. A review. Medicine;50:543-550.

Hackam DG, Khan NA, Hemmelgarn BR, Rabkin SW, Touyz RM, Campbell NR, Padwal R, Campbell TS, Lindsay MP, Hill MD, Quinn RR, Mahon JL, Herman RJ, Schiffrin EL, Ruzicka M, Larochelle P, Feldman RD, Lebel M, Poirier L, Arnold JM, Moe GW, Howlett JG, Trudeau L, Bacon SL, Petrella RJ, Milot A, Stone JA, Drouin D, 
Boulanger JM, Sharma M, Hamet P, Fodor G, Dresser GK, Carruthers SG, Pylypchuk G, Burgess ED, Burns KD, Vallée M, Prasad GV, Gilbert RE, Leiter LA, Jones C, Ogilvie RI, Woo V, McFarlane PA, Hegele RA, Tobe SW \& Canadian Hypertension Education Program 2010. The 2010 Canadian Hypertension Education Program recommendations for the management of hypertension: part 2 - therapy. Can J Cardiol;26(5) :249-258.

Hamet P, Tremblay J, Pang SC, Walter SV \& Wen YI 1985. Primary vs secondary events in hypertension. Can J Physiol Pharmacol;63:380-386.

Hamet P 1996. Environmentally-regulated genes of hypertension. Clin Exp Hypertens;18:267278.

Hamet P, Pausova Z, Adarichev V, Adaricheva K \& Tremblay J 1998. Hypertension : genes and environment. J Hypertens; $16: 397-418$.

Hamet P \& Tremblay J 2002. Genetic determinants of the stress response in cardiovascular disease. Metabolism;51(6 suppl 1):15-24.

Hassan MO, Bayoumi RA, Lopez-Alvarenga JC, Snieder H, Jaju D, Al-Yahyaee S, Al-Hadabi S, Comuzzie AG \& Albarwani S 2009. Heritability of hemodynamic reactivity to laboratory stressors in a homogenous Arab population: 'Oman Family Study'. Twin Res Hum Genet;12(6):541-548.

Havlik RJ, Garrison RJ, Feinleib M, Kannel WB, Castelli WP \& McNamara PM 1979. Blood pressure aggregation in families. Am J epidemiol;110:304-312.

Hata T, Ogihara T, Maruyama A, Mikami H, Nakamaru M, Naka T, Kumahara Y \& Nugent CA 1982. The seasonal variation of blood pressure in patients with essential hypertension. Clin Exp Hypertens;A4:341-354.

Hemmelgarn BR, Cehn G Walker R McAlister FA, Quan H, Tu K, Khan N \& Campbell N 2008. Trends in anthypertensive drug prescriptions and physician visits in Canada between 1996 and 2006. Can J Cardiol;24:507-512.

Henry JP 1992. Biological basis of the stress response. Int Physiol Behav Sci;27:66-83.

Holland WW \& Humerfelt S 1964. Measurement of blood pressure: comparison of intraarterial and cuff values. Br Med J;2(5419):1241-1243.

Huetteman DA \& Bogie H 2009. Direct blood pressure monitoring in laboratory rodents via implantable radio telemetry. Methods Mol Biol;573:57-73.

Irvine RJ, White J \& Chan R 1997. The influence of restraint on blood pressure in the rat. J Pharmacol Toxicol Methods;38:157-162.

Joffres MR, Hamet P, Rabkin SW, Gelskey D, Hogan K \& Fodor G 1992. Prevalence, control and awareness of high blood pressure among Canadian adults. Canadian Heart Health Surveys Research Group. Can Med Assoc J;146(11) :1997-2005.

Kanayama N, Khatun S, Belayet H, She L \& Terao T 1999. Chronic local cold stress to the soles induces hypertension in rats. Am. J Hypertens;12:1124-1129.

Karasek RA, Theorell T, Schwartz JE, Schnall PL, Pieper CF \& Michela JL 1988. Job characteristics in relation to the prevalence of myocardial infarction in the US Health Examination Survey (HES) and the Health and Nutrition Examination Survey (HANES). Am J Public Health;78:910-918.

Koepke JP \& DiBona GF 1985. Central beta-adrenergic receptors mediate renal nerve activity during stress in conscious spontaneously hypertensive rats. Hypertension;7:350-356.

Korner PI 2010. The phenotypic patterns of essential hypertension are the key to identifying "high blood pressure" genes. Physiol Res;59(6):841-857. 
Kramer K, Kinter L, Brockway BP, Voss H-P, Remie R \& Van Zutphen BLM 2001. The use of radiotelemetry in small laboratory animals: Recent advances. Contemporary topics;40(1):8-16.

Krege JH, Hodgin JB, Hagaman JR \& Smithies O 1995. A noninvasive computerized tail-cuff system for measuring blood pressure in mice. Hypertension;25:1111-1115.

Kuneš J, Demin AN, Jelinek J, Capek K \& Belkaniya GS 1990. Stress hypertension in monkeys. Physiol Bohemoslov;30:417-423.

Kuneš J, Tremblay J, Bellavance F \& Hamet P 1991. Influence of environmental temperature on the blood pressure of hypertensive patients in Montreal. Am J Hypertens;4:422426.

Kuneš J, Dobešová Z, Musilová A, Zídek V, Vorlíček J, Pravenec M, Křen V \& Zicha J 2008. Hemodynamic characterization of recombinant inbred strains: twenty years later. Hypertens Res;31:1659-1668.

Kurtz TW, Griffin KA, Bidani AK, Davisson RL \& Hall JE 2005. Recommendations for blood pressure measurement in humans and experimental animals. Part 2: Blood pressure measurement in experimental animals. A statement for professionals from the subcommittee of professional and public education of the American heart association council on high blood pressure research. Hypertension;45:299-310.

Kurtz TW 2010. Genome-wide association studies will unlock the genetic basis of hypertension. Con side of the argument. Hypertension;56:1021-1025.

Kvetnansky R, Weise VK \& kopin IJ 1970. Elevation of adrenal tyrosine hydroxylase and phenylethanolamine-N-methyl transferase by repeated immobilization in rats. Endocrinology;87:744-749.

Kwitek AE, Tonellato PJ, Chen D, Gullings-Handley J, Cheng YS, Twigger S, Scheetz TE, Casavant TL, Stoll M, Nobrega MA, Shiozawa M, Bento Soares M, Sheffield VC \& Jacob HJ 2001. Automated construction of high-density comparative maps between rat, human, and mouse. Genome Res;11:1935-1943.

Lawes CM, Vander HS \& Rodgers A 2008. Global burden of blood-pressure-related disease, 2001. Lancet;371(9623):1513-1518.

Leenen FH, Dumais J, McInnis NH, Turton P, Stratychuk L, Nemeth K, Lum-Kwong MM \& Fodor G 2008. Results of the Ontario survey on the prevalence and control of hypertension. Can Med Assoc J; 178(11):1441-1449.

Lewington S, Clark R, Qizilbash N, Peto R \& Collins R 2002. Age-specific relevance of usual blood pressure to vascular mortality: a meta-analysis of individual data for one million adults in 61 prospective studies. Lancet;360:1903-1913.

Lynch M \& Walsh B 1997. Genotype X environment interaction. In Genetics and analysis of quantitative traits. pp. 657-685. Sinauer and Associates Publisher, ISBN-0-87893-4812, Sunderland (MA).

Malo D, Schlager G, Tremblay J \& Hamet P 1989. Thermosensitivity, a possible new locus involved in genetic hypertension. Hypertension;14:121-128.

Malo D, Pang SC, Schlager G, Tremblay J \& Hamet P 1990. Decrease of blood pressure in spontaneously hypertensive mice by heat treatment. Am J Hypertens;3:400-404.

Marazziti D, Di Muro A \& Castrogiovanni P 1992. Psychological stress and body temperature changes in humans Physiol Behav;52:393-395. 
Markovitz JH, Matthews KA, Kannel WB, Cobb JL \& D’Agostino RB 1993. Psychological predictors of hypertension in the Framingham study. Is there a tension in hypertension? JAMA;270:2439-2443.

Markel' AL 1985. Genetic model of stress-induced arterial hypertension. Izv Akad Nauk SSSR Biol;3:466-469.

Matthews KA, Woodall KL \& Allen MT 1993. Cardiovascular reactivity to stress predicts future blood pressure status. Hypertension;22:479-485.

McMurtry JP \& Wexler BC 1981. Hypersensitivity of spontaneously hypertensive rats (SHR) to heat, ether and immobilization. Endocrinology;108:1730-1735.

McMurtry JP \& Wexler BC 1983. Hypersensitivity of spontaneously hypertensive rats to heat and ether before the onset of high blood pressure. Endocrinology;112:166-171.

Middlekauff HR, Nguyen AH, Negrao CE, Nitasche EU, Hoh CK, Natterson BA, Hamilton MA, FOnarow GC, Hage A \& Moriguchi JD 1997. Impact of acute mental stress on sympathetic nerve activity and regional blood flow in advance heart failure. Implications for 'triggering' adverse cardiac events. Circulation;96:1835-1842.

Mills PA, Huetteman DA, Brockway BP, Zwiers LM, Gelsema AJM, Schwartz RS \& Kramer $\mathrm{K} 2000$. A new method for measurement of blood pressure, heart rate, and activity in the mouse by radiotelemetry. J Appl Physiol;88:1537-1544.

Mitra A, Crump EM, Alvers KM, Robertson KL \& Rowland NE 2011. Effect of high-fat diet on stress responsiveness in borderline hypertensive rats. Stress;14(1):42-52.

Morales-Ballejo HM, Eliot RS, Boone JL \& Hughes JS 1988. Psychophysiologic stress testing as a predictor of mean daily blood pressure. Am Heart j;116 (2 pt 2):673-681.

Morley RM, Conn CA Kluger MJ \& Vander AJ 1990. Temperature regulation in biotelemetered spontaneously hypertensive rats. Am J Physiol;258:R1064-1069.

Mozaffari MS, Jirakulsomchok S, Shao ZH \& Wyss JM 1991. High-NaCl diets increase natriuretic and diuretic responses in salt-resistant but not salt-sensitive SHR. Am J Physiol;260:F890-F897.

Ohlin B, Berglund G, Nilsson PM \& Melander O 2008. Job strain, job demands and adrenergic beta1-receptor-polymorphism: a possible interaction affecting blood pressure in men. J Hypertens;26(8):1583-1589.

Okamoto K \& Aoki K 1963. Development of a strain of spontaneously hypertensive rats. Jpn Circ J;27:282-293.

O'Leary DS \& Wang G 1994. Impaired thermoregulatory cutaneous vasodilation in spontaneously hypertensive rats. J Appl Physiol;77 :692-696.

Omboni S, Smit AAJ \& Wieling W 1995. Twenty four hour continuous non-invasive finger blood pressure monitoring: a novel approach to the evaluation of treatment in patients with autonomic failure. Br Heart J;73:290-292.

Parati G, Frattola A, Di Rienzo M \& Mancia G 1996. Blood pressure variability. Importance in research and in clinical hypertension. Arq Bras Cardiol;67:131-133.

Pausova Z, Tremblay J \& Hamet P 1999. Gene-environment interactions in hypertension. Curr Hypertens Rep;1 :42-50.

Pausova Z, Syme C, Abrahamowicz M, Xiao Y, Leonard GT, Perron M, Richer L, Veillette S, Smith GD, Seda O, Tremblay J, Hamet P, Gaudet D \& Paus T 2009. A common variant of the FTO gene is associated with not only increased adiposity but also elevated blood pressure in French Canadians. Circ Cardiovasc Genet;2(3):260-269. 
Peñaz J 1973. Photoelectric measurement of blood pressure, volume and flow in the finger. Digest of the International Conference on Medicine and Biological Engineering:104.

Pickering TG, Hall JE, Appel LJ, Falkner BE, Graves J, Hill MN, Jones DW, Kurtz T, Sheps SG \& Roccella EJ 2005. Recommendations for blood pressure measurement in humans and experimental animals. Part 1: Blood pressure in humans. A statement for professionals from the subcommittee of professional and public education of the American Heart Council on High Blood Pressure Research. Hypertension;45:142161.

Price JM \& Wilmoth FR 1990. Elevated body temperature and increased blood vessel sensitivity in spontaneously hypertensive rats. Am J Physiol;258:H946-H953.

Rao F, Zhang L, Wessel J, Zhang K, Wen G, Kennedy BP, Rana BK, Das M, Rodriguez-Flores JL, Smith DW, Cadman PE, Salem RM, Mahata SK, Schork NJ, Taupenot L, Ziegler MG \& O'Connor DT 2008. Adrenergic polymorphism and the human stress response. Ann N Y Acad Sci;1148:282-296.

Rose G 1961. Seasonal variation in blood pressure in man. Nature;189:235.

Rothwell PM 2010. Limitations of the usual blood pressure hypothesis and importance of variability, instability, and episodic hypertension. Lancet;375:938-948.

Rothwell PM, Howard SC, Dolan E, O'Brien E, Dobson JE, Dahlöf B, Sever PS \& Poulter NR 2010. Prognostic significance of visit-to-visit variability, maximum systolic blood pressure, and episodic hypertension. Lancet;375:895-905.

Sakamoto H, Imataka K, Nishimura H \& Fujii J 1992. Hematological and pressor hormone responses to mental stress in essential hypertensive patients: a comparison with isometric handgrip exercise. Hypertens Res;15:33-39.

Schlager G 1974. Selection of blood pressure levels in mice. Genetics;76:537-549.

Schnall PL, Pieper C, Schwartz JE, Karasek RA, Schlussel Y, Devereux RB, Ganau A, Alderman M, Warren K \& Pickering TG 1990. The relationship between 'job strain', workplace diastolic blood pressure, and left ventricular mass index. Results of a case-control study. JAMA;263:1929-1935.

Šedová L, Bérubé J, Gaudet D, Dumont M, Tremblay J, Hamet P \& Pausová Z 2004. Dietinduced obesity delays cardiovascular recovery from stress in spontaneously hypertensive rats. Obes Res;12:1951-1958.

Selye H 1956. The stress of life. Pp. 25-43. McGraw Hill, New-York.

Singer RC, Harker CT, Vander AJ \& Kluger MJ 1986. Hyperthermia induced by open-field stress is blocked by salicylate. Physiol Behav;36:1179-1182.

Snow AE \& Horita A 1982. Interaction of apomorphine and stressors in the production of hyperthermia in the rabbit. J Pharmacol Exp Therap;220:335-339.

Stoll M \& Jacob HJ 2001. Genetic rat models of hypertension: Relationship to human hypertension. Curr Hypertens Rep;3:157-164.

Stuart J \& Eilkelboom R 1979. Stress masls the hypothermic effect of naloxone in rats. Life Sci;25:1165-1172.

Thayer JF, Yamamoto SS \& Brosschot JF 2010. The relationship of autonomic imbalance, heart rate variability and cardiovascular disease risk factors. Int J Cardiol;141(2):122131.

Thifault S, Šeda O, Sun Y, Fortin A, Skamene E, Lalonde R, Tremblay J \& Hamet P 2008. Genetic determinants of emotionality and stress response in $\mathrm{AcB} / \mathrm{BcA}$ recombinant 
congenic mice and in silico evidence of convergence with cardiovascular candidate genes. Hum Mol Genet;17:331-344.

Tobin M, Sheehan N, Samani N \& Burton PP 2007. The genetic epidemiology of hypertension. In Genetics of Hypertension. Birkenhager WH \& Reid J Eds, pp. 5-28. Elsevier, ISBN-9780444514561, Amsterdam, The Netherlands.

Trimarco B, Ricciardelli B, De Luca N, De Simone A, Cuocolo A, Galva MD, Picotti GB \& Condorelli M 1985. Participation of endogenous catecholamines in the regulation of left ventricular mass in progeny of hypertensive parents. Circulation;1:38-46.

Van Vliet BN, Chafe LL \& Montani JP 2003. Characteristics of $24 \mathrm{~h}$ telemetered blood pressure in eNOS-knockout and C57Bl/6J control mice. J Physiol;549(pt1):313-325.

Ward R 1990. Familial aggregation and genetic epidemiology of blood pressure. In Hypertension: Pathophysiology, Diagnosis and Management. Laragh JH \& Brenner BM, pp. 81-100. Raven Press, ISBN-10 0781701570, New York.

Weinberger MH 1990. Clinical studies of the role of dietary sodium in blood pressure. In Hypertension: Pathophysiology, Diagnosis and Management. Laragh JH \& Brenner BM, pp. 1999-2010. Raven Press, ISBN-10 0781701570, New York.

Wesseling KH, De Wit B, Van der Hoeven GMA, Van Goudoever J \& Settels JJ 1995. Physiocal, calibrating finger vascular physiology for Finapres. Homeostasis;36 :6782.

Widgren BR, Wikstrand J, Berglund G \& Andersson OK 1992. Increased response to physical and mental stress in men with hypertensive parents. Hypertension;20:606611.

Wilkins K, Campbell NR, Joffres MR, McAlister FA, Nichol M, Quach S, Johansen HL \& Tremblay MS 2010. Blood pressure in Canadian adults. Health Rep;21(1) :37-46.

Williams JR, Harrison TR \& Grollman A 1939. A simple method for determining the systolic blood pressure of the unanesthetized rat. J CLin Invest;18:373-376.

Wilson JR, Wilson LM \& Dicara LV 1977. Evidence for an elevation in thermoregulatory setpoint in the SHR. Proc 2nd Int Symposium on SHR;6:376-384.

Wright G, Knecht E \& Toraason M 1978. Cardiovascular effects of whole-body heating on spontaneously hypertensive rats. J Appl Physiol;45:521-527.

Yamamoto J, Nakai M \& Natsume T 1987. Cardiovascular responses to an acute stress in young-to-old spontaneously hypertensive rats. Hypertension;4:362-370.

Yamori Y, Matsumoto M, Yamabe H \& Okamoto K 1969. Augmentation of spontaneous hypertension by chronic stress in rats. Jpn Circ J;33:399-409.

Yu SF, Zhou WH, Jiang KY, Gu GZ \& Wang S 2008. Job stress, gene polymorphism of beta2AR, and prevalence of hypertension. Biomed Environ Sci;21(3):239-246.

Zhao X, Ho D, Gao S, Hong C, Vatner DE \& Vatner SF 2011. Arterial pressure monitoring in mice. Curr Protoc Mouse Biol;1:105-122. 


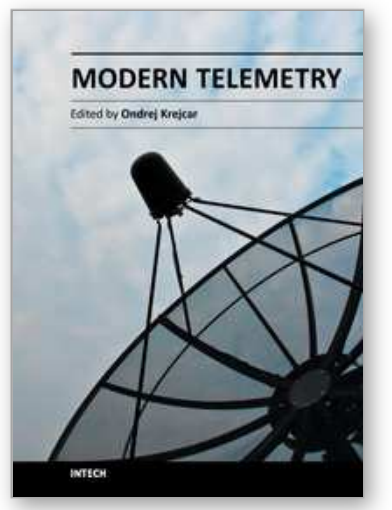

\author{
Modern Telemetry \\ Edited by Dr. Ondrej Krejcar
}

ISBN 978-953-307-415-3

Hard cover, 470 pages

Publisher InTech

Published online 05, October, 2011

Published in print edition October, 2011

Telemetry is based on knowledge of various disciplines like Electronics, Measurement, Control and Communication along with their combination. This fact leads to a need of studying and understanding of these principles before the usage of Telemetry on selected problem solving. Spending time is however many times returned in form of obtained data or knowledge which telemetry system can provide. Usage of telemetry can be found in many areas from military through biomedical to real medical applications. Modern way to create a wireless sensors remotely connected to central system with artificial intelligence provide many new, sometimes unusual ways to get a knowledge about remote objects behaviour. This book is intended to present some new up to date accesses to telemetry problems solving by use of new sensors conceptions, new wireless transfer or communication techniques, data collection or processing techniques as well as several real use case scenarios describing model examples. Most of book chapters deals with many real cases of telemetry issues which can be used as a cookbooks for your own telemetry related problems.

\title{
How to reference
}

In order to correctly reference this scholarly work, feel free to copy and paste the following:

Pierre Dumas, Dan Chiche, Johanne Tremblay, Onď̌ej Seda, Junzheng Peng and Pavel Hamet (2011). RadioTelemetry in Biomedical Research - Radio-Telemetry Blood Pressure Measurements in Animal Models of Hypertension, How It Revolutionized Hypertension Research, Modern Telemetry, Dr. Ondrej Krejcar (Ed.), ISBN: 978-953-307-415-3, InTech, Available from: http://www.intechopen.com/books/modern-telemetry/radiotelemetry-in-biomedical-research-radio-telemetry-blood-pressure-measurements-in-animal-models-

\section{INTECH}

open science | open minds

\section{InTech Europe}

University Campus STeP Ri

Slavka Krautzeka 83/A

51000 Rijeka, Croatia

Phone: +385 (51) 770447

Fax: +385 (51) 686166

www.intechopen.com

\section{InTech China}

Unit 405, Office Block, Hotel Equatorial Shanghai

No.65, Yan An Road (West), Shanghai, 200040, China 中国上海市延安西路65号上海国际贵都大饭店办公楼405单元

Phone: +86-21-62489820

Fax: $+86-21-62489821$ 
(C) 2011 The Author(s). Licensee IntechOpen. This is an open access article distributed under the terms of the Creative Commons Attribution 3.0 License, which permits unrestricted use, distribution, and reproduction in any medium, provided the original work is properly cited. 